\title{
PENERAPAN VALUE ENGINEERING PADA PEKERJAAN KONSTRUKSI STUDI KASUS PROYEK PEMBANGUNAN RUMAH SAKIT UMUM PROVINSI SUMATERA SELATAN
}

\author{
Ani Firda ${ }^{l}$, Sandi Saputra ${ }^{2}$ \\ ${ }^{1}$ Universitas Tridinanti Palembang \\ ${ }^{2}$ Universitas Tridinanti Palembang \\ E-mail: $\underline{\text { ani.firda@gmail.com }}$
}

\begin{abstract}
Palembang is undergoing development in all fields, along with the increasing population, resulting in an increase in the need for public facilities and infrastructure, such as the Palembang Provincial General Hospital Development Project, control and supervision of costs for the project are needed, because project cost control is important One of them is in the process of managing project costs by using the Value Engineering method, with the aim of the government budget being controlled and this research focused on controlling costs in column and beam structure work. The Value Engineering stage starts from making BreakDown Jobs that are associated with the application of Pareto law and making analysis functions and fast diagraming. Cost savings of the South Sumatra Provincial General Hospital Project Construction obtained from the application of Value Engineering to the Column and Beams work costs of Rp. 3,737,843,286 or $7.02 \%$.
\end{abstract}

Keywords: Value Engineerin, analysis, Project management

\begin{abstract}
ABSTRAK
Palembang sedang mengalami pembangunan di segala bidang, seiring dengan semakin bertambahnya jumlah penduduk maka mengakibatkan meningkatnya kebutuhan terhadap sarana dan prasarana umum, seperti halnya Proyek Pembangunan Rumah Sakit Umum Provinsi Palembang, diperlukan pengendalian dan pengawasan biaya untuk proyek tersebut, karena pengendalian biaya proyek merupakan hal penting dalam proses pengelolaan biaya proyek salah satunya dengan menggunakan metode Value Engineering, dengan tujuan anggaran yang dikeluarkan pemerintah dapat terkendali dan penelitian ini difokuskan pada pengendalian biaya pada pekerjaan struktur kolom dan balok. Tahapan Value Engineering dimulai dari membuat BreakDown Pekerjaan yang dihubungkan dengan penerapan hukum pareto serta membuat analisis fungsi dan fast diagraming. Penghematan biaya Proyek Pembangunan Rumah Sakit Umum Provinsi Sumatera Selatan yang diperoleh dari penerapan Rekayasa Nilai (Value Engineering) pada pekerjaan Kolom dan Balok biaya sebesar Rp. 3.737.843.286 atau sebesar 7,02 \%.
\end{abstract}

Kata kunci: Value Engineering, analisis, Manajemen Proyek 


\section{PENDAHULUAN}

Dewasa ini Indonesia, khususnya Kota Palembang sedang mengalami pembangunan di segala bidang, seiring dengan semakin bertambahnya jumlah penduduk maka mengakibatkan meningkatnya kebutuhan terhadap sarana dan prasarana umum, seperti halnya pembangunan sarana umum seperti Rumah Sakit Umum yang telah direncanakan dan dilaksanakan dengan matang oleh pemerintah Palembang.

Rumah sakit adalah institusi pelayanan kesehatan yang menyelenggarakan pelayanan kesehatan perorangan secara paripurna yang menyediakan pelayanan rawat inap, rawat jalan dan gawat darurat. Untuk menyediakan pelayanan tersebut maka diperlukan perencanaan konstruksi pembangunan yang benar-benar matang dan terkontrol agar tercapainya pembangunan Rumah Sakit yang dapat melayani dan menyediakan fasilitas yang diinginkan masyarakat umum.

Dalam pembangunan suatu proyek konstruksi, seperti halnya Proyek Pembangunan Rumah Sakit Umum Provinsi Palembang. Diperlukan pengendalian dan pengawasan biaya untuk proyek tersebut, karena pengendalian biaya proyek merupakan hal penting dalam proses pengelolaan biaya proyek. Dalam kegiatan suatu proyek pasti terdapat masalah sepertipenggunaan material yang boros, tenaga kerja yang kurang terampil dam waktu penyelesaian proyek yang tidak tepat sehingga menyebabkan pemborosan biaya yang idak sesuai dengan perencanaan.

Dalam Manajemen Konstruksi (MRK) terdapat suatu disiplin ilmu teknik sipil yang digunakan untuk mengefisiensikan biaya, ilmu tersebut dikenal dengan nama Rekayasa Nilai (Value Engineering). Rekayasa Nilai (Value Engineering) adalah suatu cara pendekatan yang kreatif dan terencana dengan tujuan untuk mengidentifikasikn dan mengefisiensikan biaya yang tidak perlu. Rekayasa Nilai (Value Engineering) digunakan untuk mencari alternatif-alternatif atau ide-ide yang bertujuan untuk menghasilkan biaya yang lebih baik/lebih rendah dari harga yang telah direncanakan sebelumnya dengan batasan fungsional dan mutu pekerjaan.

Dikarenakan kondisi perekonomian saat ini, maka pada pembangunan proyek yang sedang berjalan membutuhkan alokasi dana yang cukup besar perlu dipertimbangkan lagi apakah desain yang digunakan telah optimal. Maka diperlukan suatu Penerapan Sistem Value Engineering Pada Proyek Pembangunan Rumah Sakit Umum Provinsi Sumatera Selatan. Pada penelitian ini difokuskan pada penelitian pada struktur atas yang dibatasi pada pekerjaan struktur kolom dan balok. Dengan harapan dapat diketahui kekurangan dan kelemahan dari suatu proyek yang nantinya dapat menjadi masukan bagi kontraktor pelaksana agar lebih baik lagi dalam merencanakan suatu struktur konstruksi bangunan.

\section{METODE PENELITIAN}

Metode penelitian yang digunakan untuk mengetahui bahwa penerapan Value Engineering pada Proyek Pembangunan Rumah Sakit Umum Provinsi Sumatera Selatan dapat mengefisiensikan biaya proyek yang dianggap memiliki biaya lebih mahal dibandingkan dengan bangunan konvensional. Pendekatan penelitian yang digunakan dalam penelitian ini adalah pendekatan komparatif yaitu "membandingkan sutu variabel atau lebih dengan sampel besar, atau penelitian dilakukan dengan mengkaji beberapa fenomena sosial".

\section{Subjek dan Objek Penelitian}

Subjek penelitian yang diambil adalah Proyek Pembangunan Rumah Sakit Umum Provinsi Sumatera Selatan di Jalan Kolonel Haji Burlian Km. 5, Sukabangun Palembang. Objek penelitian pada proyek ini adalah meninjau Kolom dan balok dari segi harga dan membandingkan harga kolom 
dan balok non-Precast dengan harga kolom dan balok Precast.

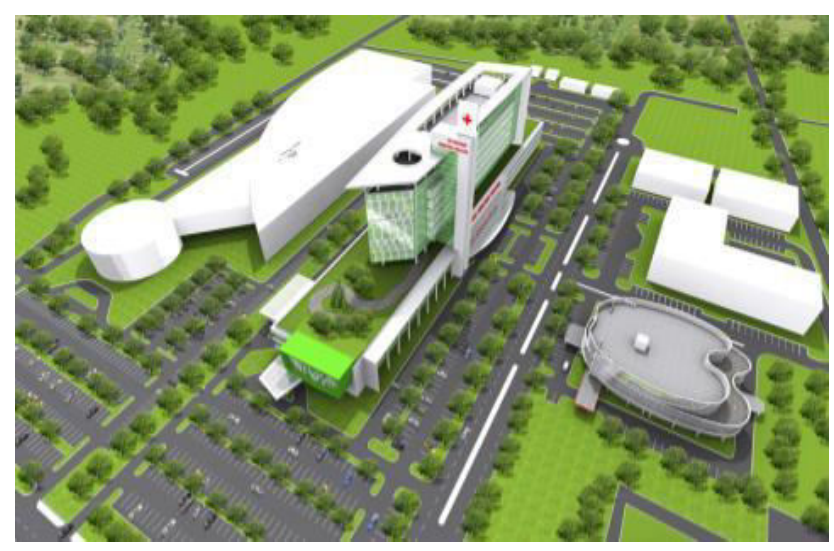

Gambar 1. Layouts Rumah Sakit Umum Provinsi Sumatera Selatan

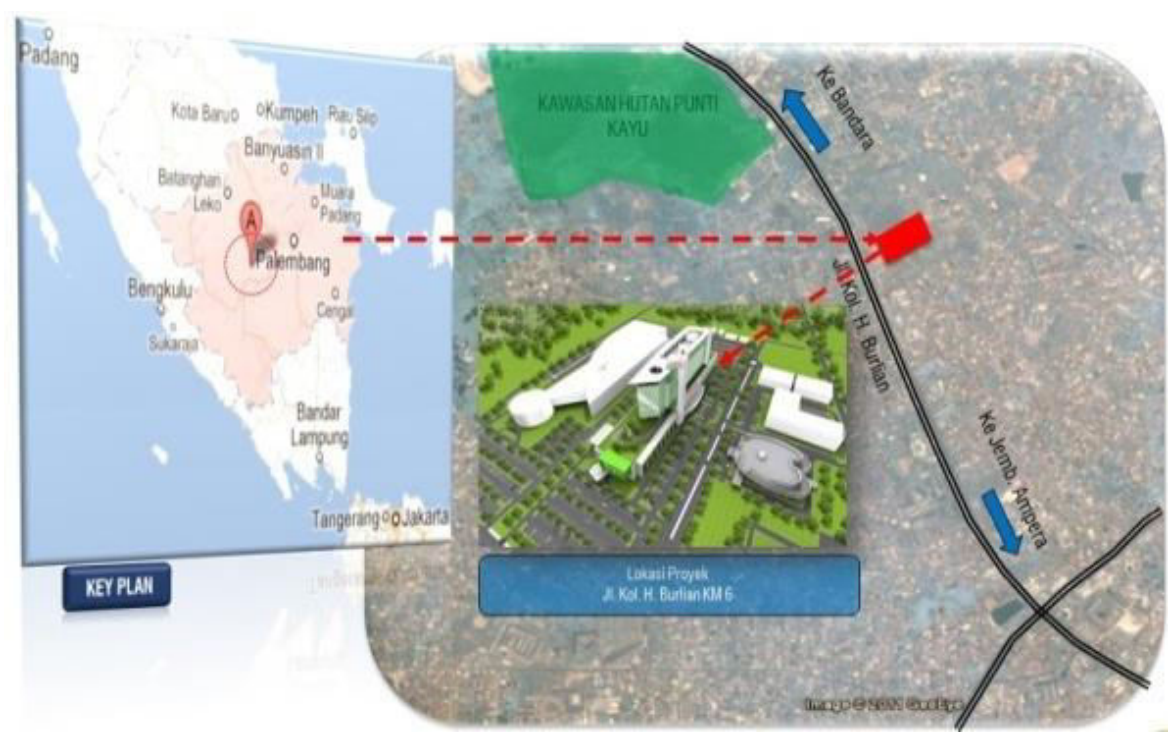

Gambar 2. Peta Lokasi Rumah Sakit Umum Provinsi Sumatera Selatan

\section{Jenis Data}

\section{Data Primer}

Data Primer adalah data yang di ambil langsung dari objek penelitian yaitu berupa pertanyaanpertanyaan yang disusun dalam kuesioner dan diberikan kepada pihak-pihak yang terkait dalam Proyek Pembangunan Rumah Sakit Umum Provinsi Sumatera Selatan.

2. Data Sekunder

Data Sekunder adalah data yang digunakan untuk analisis Value Engineering, seperti :
a. Gambar Struktur
b. Harga Satuan Bahan 2016
c. Bill of Quantity $(B Q)$
d. Formula Harga Satuan Beton Bertulang Precast 


\section{Sumber Data}

1. Dokumentasi

Dokumentasi ditujukan untuk memperoleh daya langsung dari tempat penelitian, meliputi Rencana Anggaran Biaya (RAB), dan data yang relavan dengan penelitian.

2. Kuesioner

Kuesioner adalah suatu teknik pengumpulan informasi yang memungkinkan analis mempelajari sikap-sikap, keyakinan, perilaku, dan karakteristik beberapa orang utama di dalam organisasi yang bisa terpengaruh oleh sistem yang diajukan atau oleh sistem yang sudah ada.

\section{Teknik Analisa Data}

Analisa yang digunakan untuk menjawab rumusan masalah pada penelitian ini adalah analisis Value Engineering (VE).

\section{Tahap Pra-Analisa}

Tahapan ini merupakan awal dari penelitian yang dilakukan, dan aktifitas Value Engineering yang dilakukan pada tahap ini adalah :

a) Memahami Konsep Desain eksisting

b) Mengidentifikasikan masalah dan kendala-kendala

c) Mengumpulkan informasi sebanyak-banyaknya berkaitan dengan proyek.

d) Mengumpulkan data sebanyak-banyaknya dari proyek yang berkaitan dengan penelitian.

e) Melakukan tahapan wawancara dengan pelaksana agar lebih memahami tentang proyek yang akan diteliti.

\section{Tahap Analisa}

Dalam penelitian ini dilakukan perhitungan biaya antara kolom dan balok non-Precast dengan kolom dan balok precast. Tahap ini merupakan tahap untuk memperkirakan nilai kegunaan dari suatu subsistem dan diperkirakan biaya (cost) untuk subsistem tersebut. Aktifitas Value Engineering pada tahap ini adalah :

a) Menentukan komponen item pekerjaan yang akan diteliti

b) Mengidentifikasi permasalahan yang akan diteliti

c) Membuat analisa pekerjaan kolom dan balok non-Precast dan precast.

d) Menghitung biaya pekerjaan kolom dan balok non-Precast. Peneliti menghitung biaya $1 \mathrm{~m}^{3}$ pekerjaan kolom dan balok non-Precast dengan harga satuan bahan tahun 2016, dengan menggunakan metode SNI.

e) Menghitung biaya pekerjaan kolom dan balok Precast.

f) Membuat perbandingan biaya pekerjaan kolom dan balok non-Precast dengan kolom dan balok precast.

g) Membuat kesimpulan dari hasil analisa alternatif.

\section{HASIL DAN PEMBAHASAN}

\section{Tahap Informasi}

Tahap pertama yang harus dilakukan dalam penerapan Value Engineering adalah mengumpulkan data umum mengenai proyek.

\section{Gambaran Umum Proyek}

1. Berikut gambaran umum proyek yang diperlukan sebagai bahan informasi untuk penerapan Value Engineering pada bangunan ini : Pembangunan Rumah Sakit UmumProvinsi Sumatera 
Selatan di Jl. Kolonel H. Burlian KM. 6 Palembang

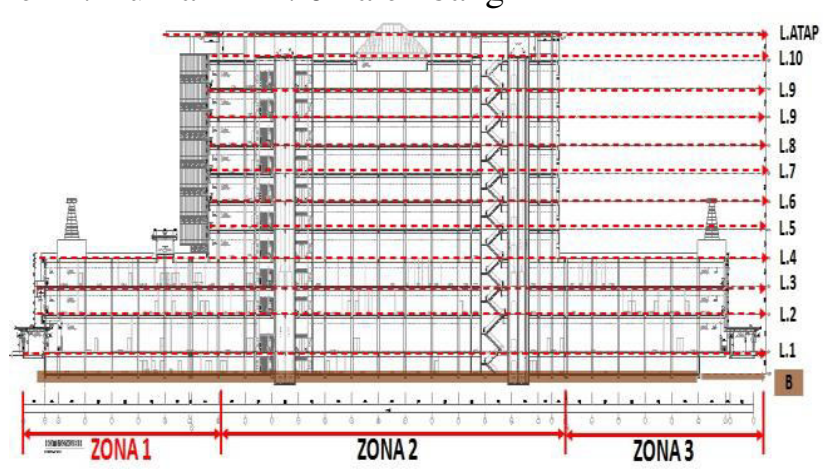

Gambar 3. Gambaran Bangunan Zona 1, Zona 2, dan Zona 3

\section{Biaya Total Keseluruhan Proyek}

Tabel 1. Rekapitulasi Biaya Struktur Proyek Tahun Anggaran 2015

\begin{tabular}{|c|c|c|}
\hline NO. & URAIAN & JUMLAH \\
\hline II & $\begin{array}{l}\text { PEKERJAAN STRUKTUR } \\
\text { 2.1 PEK. TANAH PILE } \\
\text { CAP, TIE BEAM \& PLAT } \\
\text { 2.2 PEK. STRUKTUR } \\
\text { BAWAH } \\
\text { 2.3 PEK. STRUKTUR } \\
\text { ATAS } \\
\text { 2.4 PEK. STRUKTUR } \\
\text { TANGGA }\end{array}$ & $\begin{array}{r}\mathrm{Rp} \\
49.862 .602,92 \\
\mathrm{Rp} \\
116.282 .648 .829,30 \\
\mathrm{Rp} \\
2.929 .818 .380,55\end{array}$ \\
\hline & JUMLAH A & $\begin{aligned} \mathrm{Rp} \\
119.262 .329 .812,77\end{aligned}$ \\
\hline
\end{tabular}

\section{Tahap Analisis Fungsi}

Tabel 2. Tabel Analisis Fungsi

\begin{tabular}{|c|c|c|c|}
\hline Pekerjaan & Kata Kerja & $\begin{array}{c}\text { Kata } \\
\text { Benda }\end{array}$ & Fungsi \\
\hline $\begin{array}{c}\text { Kolom \& } \\
\text { Balok } \\
\text { Precast }\end{array}$ & Mengurangi & $\begin{array}{c}\text { Anggaran } \\
\text { Biaya }\end{array}$ & Primer \\
& Menekan & Sampah & Sekunder \\
& Meminimalisasi & Peralatan & Sekunder \\
& Meminimalisasi & Bahan & Sekunder \\
\hline
\end{tabular}

Selanjutnya fungsi-fungsi pada Tabel 2 disusun dalam suatu Diagram Fast : 


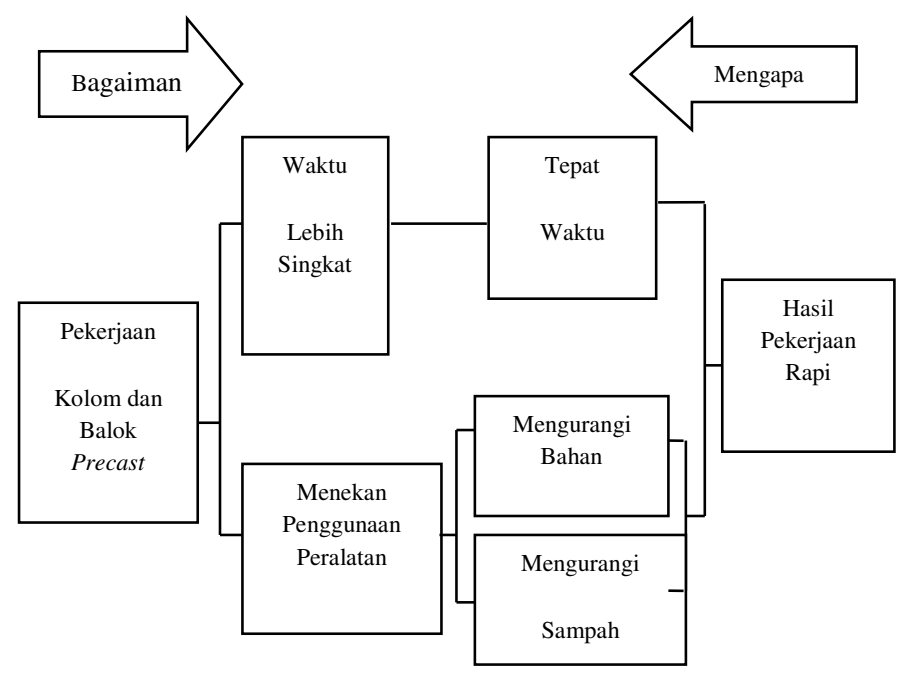

Gambar 5. Fast Diagram Pekerjaan Kolom dan Balok Precast

\section{Penerapan Hukum Pareto}

Tabel 3. Hasil Pengujian Pareto

\begin{tabular}{|c|c|c|c|c|c|}
\hline NO. & URAIAN & & JUMLAH & $\begin{array}{c}\% \\
\text { HARGA }\end{array}$ & $\begin{array}{c}\% \\
\text { KUMULATIF }\end{array}$ \\
\hline$\pi$ & $\begin{array}{l}\text { PEKERJAAN STRUKTUR } \\
\text { 2.1 PEK. STRUKTUR ATAS } \\
\text { 2.2 PEK. STRUKTUR TANGGA } \\
\text { 2.3 PEK. STRUKTUR BAWAH }\end{array}$ & $\begin{array}{l}\mathrm{Rp} \\
\mathrm{Rp} \\
\mathrm{Rp}\end{array}$ & $\begin{array}{r}116.282 .648 .829,30 \\
2.929 .818 .380,55 \\
49.862 .602,92\end{array}$ & $\begin{array}{l}97,50 \% \\
2,46 \% \\
0,04 \%\end{array}$ & $\begin{array}{l}97,50 \% \\
99,96 \% \\
100,00 \%\end{array}$ \\
\hline & JUMLAH & $\mathrm{Rp}$ & $119.262 .329 .812,77$ & & \\
\hline
\end{tabular}

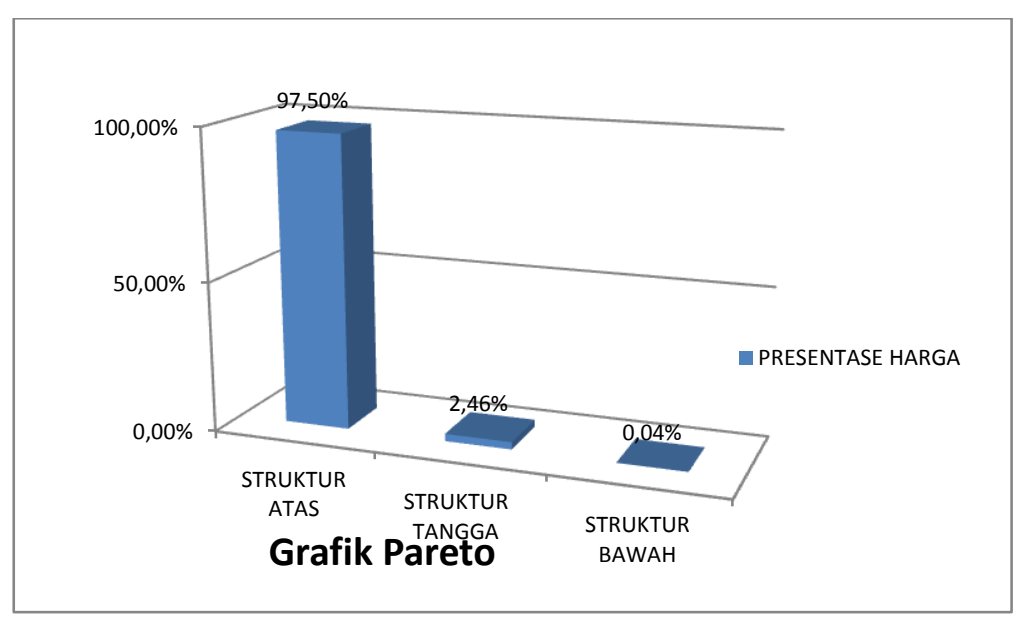

Gambar 6. Grafik Hasil Pengujian Pareto 


\section{Pemilihan Pekerjaan}

Pada penelitian ini, analisa Value Engineering lebih lanjut akan dilakukan pada perbandingan antara Kolom dan Balok non-Precast dengan kolom dan Balok Precast dari segi biaya untuk menekan anggaran biaya dan mempercepat waktu pelaksanaan proyek.

\section{Tahap Analisis Kuesioner}

1. Memperoleh data yang relevan dengan tujuan penelitian.

2. Memperoleh kesimpulan bahwa penerapan value engineering dapat diterapkan pada proyek dengan biaya yang besar dan dapat dikembangkan dan dipakai di kemudian hari.

\section{Rekapitulasi Data Populasi dan Responden}

$$
\mathrm{n}=\frac{N}{1+N e^{2}}=\frac{12}{1+12 \times 0,05^{2}}=11,65 \sim 12 \text { Responden }
$$

\section{Analisa Kuesioner}

1. Jika Skor $>50 \%=$ Cukup

2. Jika Skor $\leq 50 \%=$ Kurang

Tabel 4. Kategori Terhadap Tanggapan Responden

\begin{tabular}{|c|c|c|c|c|}
\hline 1 & Code & Jumlah Skor & Persentase & Kategori \\
\hline 1 & P-01 & 120 & $100 \%$ & Cukup \\
\hline 2 & P-02 & 0 & $0 \%$ & Kurang \\
\hline 3 & P-03 & 20 & $17 \%$ & Kurang \\
\hline 4 & P-04 & 40 & $33 \%$ & Kurang \\
\hline 5 & P-05 & 10 & $8 \%$ & Kurang \\
\hline 6 & P-06 & 120 & $100 \%$ & Cukup \\
\hline 7 & P-07 & 120 & $100 \%$ & Cukup \\
\hline 8 & P-08 & 110 & $92 \%$ & Cukup \\
\hline 9 & P-09 & 120 & $100 \%$ & Cukup \\
\hline 10 & P-10 & 120 & $100 \%$ & Cukup \\
\hline \multicolumn{2}{|c|}{ RATA-RATA PERSENTASE SKORING } & $\mathbf{6 5 \%}$ & Cukup \\
\hline
\end{tabular}

\section{Hasil Analisa Kuesioner}

Mengenai pekerjaan kolom dan balok precast, dapat mengurangi anggaran biaya, efisiensi waktu, menekan penyebaran sampah, meminimalisasikan peralatan yang digunakan, dan menghemat penggunaan bahan material sehingga Value Engineering dapat diterapkan pada proyek Pembangunan Rumah Sakit Umum Provinsi Sumatera Selatan. 


\section{Tahap Analisis Perbandingan Harga}

Tabel 5. Rencana Anggaran Biaya

\begin{tabular}{|c|c|c|c|c|c|c|c|}
\hline No. & $\begin{array}{l}\text { Uraian Pekerjaan } \\
\text { Kolom dan Balok } \\
\text { Masing-masing Tipe }\end{array}$ & Sat & Vol & $\begin{array}{l}\text { Harga Satuan } \\
\text { Non-Precast } \\
\text { (Rp) }\end{array}$ & $\begin{array}{c}\text { Harga Satuan } \\
\text { Precast } \\
\text { (Rp) }\end{array}$ & $\begin{array}{l}\text { Jumlah Harga } \\
\text { Non-Precast } \\
\text { (Rp) }\end{array}$ & $\begin{array}{l}\text { Jumlah Harga } \\
\text { Precast } \\
\text { (Rp) }\end{array}$ \\
\hline & $\begin{array}{l}\text { PEK. STRUKTUR ATAS } \\
\text { LANTAI BASEMENT } \\
\text { Zona II }\end{array}$ & & & & & & \\
\hline 1 & Pek. Kolom K.1 ( 550 x 550) & $\mathrm{m}^{3}$ & 47,64 & $6.734 .332,06$ & $6.227 .748,82$ & $320.823 .579,17$ & $296.689 .953,74$ \\
\hline 2 & $\begin{array}{l}\text { Pek. Kolom K.1B (550 x } \\
\text { 550) }\end{array}$ & $\mathrm{m}^{3}$ & 36,00 & $6.182 .676,93$ & $5.710 .913,15$ & $222.576 .369,58$ & $205.592 .873,23$ \\
\hline 3 & Pek. Kolom K.2 $(700$ × 700$)$ & $m^{3}$ & 87,47 & $7.274 .363,74$ & $6.809 .712,43$ & $636.288 .596,04$ & $595.645 .546,15$ \\
\hline 4 & Pek. Kolom K.3 $(600$ x 600) & $\mathrm{m}^{3}$ & 14,79 & $7.479 .833,50$ & 6.980.758,67 & $110.626 .737,50$ & $103.245 .420,77$ \\
\hline 5 & Pek. Kolom K.4 (500 x 600) & $\mathrm{m}^{3}$ & 5,92 & $7.479 .833,50$ & $6.980 .758,67$ & $44.280 .614,33$ & $41.326 .091,34$ \\
\hline 6 & $\begin{array}{l}\text { Pek. Kolom K.6 (1000 x } \\
\text { 1000) } \\
\text { Zona III }\end{array}$ & $\mathrm{m}^{3}$ & 4,48 & $6.136 .427,15$ & $5.778 .415,34$ & 27.491.193,65 & $25.887 .300,74$ \\
\hline 1 & Pek. Kolom K.1 (550 x 550) & $\mathrm{m}^{3}$ & 44,47 & $6.734 .332,06$ & $6.227 .748,82$ & $299.475 .746,55$ & $276.947 .989,99$ \\
\hline 2 & $\begin{array}{l}\text { Pek. Kolom K.1A (550 x } \\
\text { 550) }\end{array}$ & $\mathrm{m}^{3}$ & 8,47 & $6.734 .332,06$ & $6.227 .748,82$ & $57.039 .792,52$ & $52.749 .032,50$ \\
\hline 3 & $\begin{array}{l}\text { Pek. Kolom K.1B (550 x } \\
\text { 500) }\end{array}$ & $\mathrm{m}^{3}$ & 14,84 & $6.182 .676,93$ & $5.710 .913,15$ & $91.750 .925,68$ & $84.749 .951,08$ \\
\hline & & & & & $\overline{\text { Total Jumlah }}$ & $1.810 .353 .555,04$ & $1.682 .834 .159,54$ \\
\hline & & & & & Selisih & \multicolumn{2}{|c|}{$127.519 .395,49$} \\
\hline
\end{tabular}

Tabel 6. Rekapitulasi Perbandingan Harga

\begin{tabular}{|c|c|c|c|c|c|}
\hline \multirow{4}{*}{ No } & \multirow{4}{*}{ URAIAN PEKERJAAN } & \multicolumn{2}{|c|}{ Jumlah Biaya } & \multicolumn{2}{|c|}{ Jumlah Biaya } \\
\hline & & \multicolumn{2}{|c|}{ Kolom dan Balok } & \multicolumn{2}{|c|}{ Kolom dan Balok } \\
\hline & & \multicolumn{2}{|c|}{ Non-Precast } & \multicolumn{2}{|c|}{ Precast } \\
\hline & & \multicolumn{2}{|c|}{ (Rp) } & \multicolumn{2}{|c|}{ (Rp) } \\
\hline 1 & Lantai Basement & $\mathrm{Rp}$ & 1.810 .353 .555 & $\mathrm{Rp}$ & 1.682 .834 .160 \\
\hline 2 & Lantai 1 & $\mathrm{Rp}$ & 8.872 .563 .133 & $\mathrm{Rp}$ & 8.238 .543 .358 \\
\hline 3 & Lantai 2 & $\mathrm{Rp}$ & 7.067 .036 .997 & $\mathrm{Rp}$ & 6.571 .980 .481 \\
\hline 4 & Lantai 3 & $\mathrm{Rp}$ & 6.719 .131 .939 & $\mathrm{Rp}$ & 6.261 .016 .882 \\
\hline 5 & Lantai 4 & $\mathrm{Rp}$ & 5.642 .537 .458 & $\mathrm{Rp}$ & 5.242 .050 .077 \\
\hline 6 & Lantai 5 & $\mathrm{Rp}$ & 3.256 .200 .763 & $\mathrm{Rp}$ & 3.033 .032 .084 \\
\hline 7 & Lantai 6 & $\mathrm{Rp}$ & 3.256 .200 .763 & $\mathrm{Rp}$ & 3.033 .032 .084 \\
\hline 8 & Lantai 7 & $\mathrm{Rp}$ & 3.224 .265 .223 & $\mathrm{Rp}$ & 3.002 .657 .255 \\
\hline 9 & Lantai 8 & $\mathrm{Rp}$ & 3.224 .265 .223 & $\overline{R p}$ & 3.002 .657 .255 \\
\hline 10 & Lantai 9 & $\mathrm{Rp}$ & 3.190 .284 .827 & $\mathrm{Rp}$ & 2.971 .311 .887 \\
\hline 11 & Lantai 10 & $\mathrm{Rp}$ & 3.140 .202 .609 & $\mathrm{Rp}$ & 2.925 .113 .322 \\
\hline
\end{tabular}


Tabel 6. Rekapitulasi Perbandingan Harga (Lanjutan)

\begin{tabular}{|c|c|c|c|}
\hline \multirow{4}{*}{ No } & \multirow{4}{*}{ URAIAN PEKERJAAN } & Jumlah Biaya & Jumlah Biaya \\
\hline & & Kolom dan Balok & Kolom dan Balok \\
\hline & & Non-Precast & Precast \\
\hline & & (Rp) & (Rp) \\
\hline 12 & Lantai Mesin Lift & 2.500 .233 .591 & 2.313 .592 .850 \\
\hline 13 & Lantai Dak Mesin Lift & 1.286 .540 .764 & 1.174 .151 .866 \\
\hline & $\overline{\text { TOTAL }}$ & 53.189 .816 .846 & 49.451 .973 .560 \\
\hline & $\overline{\text { SELISIH }}$ & $\mathrm{Rp}$ & 3.737 .843 .286 \\
\hline
\end{tabular}

\section{KESIMPULAN DAN SARAN}

Penghematan biaya Proyek Pembangunan Rumah Sakit Umum Provinsi Sumatera Selatan yang diperoleh dari penerapan Rekayasa Nilai (Value Engineering) pada pekerjaan Kolom dan Balok biaya sebesar Rp. 3.737.843.286 atau sebesar 7,02\%.

Alternatif Value Engineering pada pekerjaan Kolom dan Balok memberikan keuntungan pada Proyek Pembangunan Rumah Sakit Umum Provinsi Sumatera Selatan antara lain dapat lebih menghemat anggaran biaya, efisiensi waktu, menekan penyebaran sampah, meminimalisasikan peralatan yang digunakan, dan menghemat penggunaan bahan material.

\section{DAFTAR}

[1] Berawi, M.A (2009), Aplikasi Rekayasa Nilai//Manajemen Nilai pada industri konstruksi di Indonesia untuk peningkatan Daya saing dan inovasi. Laporan Penelitian Hibah Bersaing. Universitas Indonesia. November. Depok.

[2] Berawi, M.A. (2014). Aplikasi Value Engineering Pada Industri Konstruksi Bangunan Gedung. Penerbit Universitas Indonesia (UI-Press).

[3] Ervianto, Wulfram I. (2005). Manajemen Proyek Konstruksi, Andi Offset, Yogyakarta.

[4] Ervianto, Wulfram I. (2006). Ekplorasi Teknologi dalam Proyek Konstruksi Beton Pracetak \& Bekisting, Andi Offset. Yogyakarta.

[5] Husen, Abrar. (2009). Manajemen Proyek. Andi Offset. Yogyakarta.

[6] Kelly, J. R., S. Male, et al. (2004). Value Management of construction Project. London

[7] Krejcie,R.V \& Morgan, D.W. (1970). Determining sample size for research activities. Education and Psychological Mesurement.

[8] SAVE International Value Standard. (2007). 2007 Edition, Value Standard and Body of Knowledge

[9] Sevilla, Conseulo G, et. Al. (2007). Research Methods. Rex Printing Company

[10] Short, C. Alan, Barrett, Peter, Dye, Anne, and Sutisna, Monty. (2007). Impacts of Value Engineering on Five Capital

[11] Arts Projects, Journal on Building Research \& Information.

[12] Younker, D.L.,(2003.) A study on the development of intelligent building in Malaysia. Unpublish Thesis, Faculty of Built Environment, University of Malaysia, Kuala Lumpur, Malaysia 